University of Wollongong

Research Online

Australian Institute for Innovative Materials -

Papers

Australian Institute for Innovative Materials

$1-1-2014$

Pristine organo-imido polyoxometalates as an anode for lithium ion batteries

Rao Naumaan Nasim Khan

Tsinghua University

Nasir Mahmood

Peking University, nmahmood@uow.edu.au

Chunlin Lv

Tsinghua University

Guohui Sima

Tsinghua University

Jin Zhang

Tsinghua University

See next page for additional authors

Follow this and additional works at: https://ro.uow.edu.au/aiimpapers

Part of the Engineering Commons, and the Physical Sciences and Mathematics Commons

Research Online is the open access institutional repository for the University of Wollongong. For further information contact the UOW Library: research-pubs@uow.edu.au 


\title{
Pristine organo-imido polyoxometalates as an anode for lithium ion batteries
}

\author{
Abstract \\ Here we have designed a strategy to improve the electronic conductivities of polyoxometalates (POMs) \\ via property-oriented organic grafting for use in lithium-ion batteries (LIBS). POMs usually exhibit limited \\ electronic conductivity that hinders their use in electronic applications. Organic grafting of POMs defines \\ a valuable path for improving electronic conductivities of POMs, due to the enhanced metal to ligand \\ charge transfer (MLCT) via d- $\pi$ electronic interactions, and results in their feasible application in LIBs. \\ Comparative practical and theoretical study of the effect of functional groups revealed that grafting of the \\ remote electron withdrawing group (-SCN) on POMs via organo-imidoylization along with lower values of \\ lowest unoccupied molecular orbitals (LUMO) results in an enhanced performance as Mo6-SCN shows \\ initial discharge capacity of $\sim 1678 \mathrm{~mA} \mathrm{~h} \mathrm{g-1}$ with $\sim 85 \%$ capacity retention and coulombic efficiency \\ $\sim 100 \%$ after 100 cycles. 2014 The Royal Society of Chemistry. \\ Keywords \\ lithium, ion, imido, batteries, pristine, polyoxometalates, organo, anode \\ Disciplines \\ Engineering | Physical Sciences and Mathematics \\ Publication Details \\ Nasim Khan, R. Naumaan., Mahmood, N., Lv, C., Sima, G., Zhang, J., Hao, J., Hou, Y. \& Wei, Y. (2014). \\ Pristine organo-imido polyoxometalates as an anode for lithium ion batteries. RSC Advances: an \\ international journal to further the chemical sciences, 4 (15), 7374-7379.

\section{Authors} \\ Rao Naumaan Nasim Khan, Nasir Mahmood, Chunlin Lv, Guohui Sima, Jin Zhang, Jian Hao, Yanglong Hou, \\ and Yongge Wei
}




\title{
Pristine organo-imido polyoxometalates as an anode for lithium ion batteries $\uparrow$
}

\author{
Rao Naumaan Nasim Khan, ț Nasir Mahmood, $t^{\mathrm{b}}$ Chunlin Lv, $\dot{t}^{\mathrm{a}}$ Guohui Sima, ${ }^{a}$ \\ Jin Zhang, ${ }^{\mathrm{a}}$ Jian $\mathrm{HaO},{ }^{\mathrm{a}}$ Yanglong Hou${ }^{\star \mathrm{b}}$ and Yongge Wei ${ }^{\star a}$
}

Here we have designed a strategy to improve the electronic conductivities of polyoxometalates (POMs) via property-oriented organic grafting for use in lithium-ion batteries (LIBs). POMs usually exhibit limited electronic conductivity that hinders their use in electronic applications. Organic grafting of POMs defines a valuable path for improving electronic conductivities of POMs, due to the enhanced metal to ligand charge transfer (MLCT) via $d-\pi$ electronic interactions, and results in their feasible application in LIBs. Comparative practical and theoretical study of the effect of functional groups revealed that grafting of the remote electron withdrawing group $(-\mathrm{SCN})$ on $\mathrm{POMs}$ via organo-imidoylization along with lower values of lowest unoccupied molecular orbitals (LUMO) results in an enhanced performance as $\mathrm{Mo}_{6}{ }^{-}$ SCN shows initial discharge capacity of $\sim 1678 \mathrm{~mA} \mathrm{~h} \mathrm{~g}^{-1}$ with $\sim 85 \%$ capacity retention and coulombic efficiency $\sim 100 \%$ after 100 cycles.

Received 13th November 2013 Accepted 6th January 2014

DOI: $10.1039 / \mathrm{c} 3 \mathrm{ra} 46645 \mathrm{k}$

www.rsc.org/advances new areas in material research due to fascinating $d-\pi$ electronic transitions within the organic-inorganic hybrids. ${ }^{13}$

POMs are good ionic conductors but their bulk electronic conductivity is negligible, hence they perform poorly in LIBs when used as electrode material independently. ${ }^{9,10}$ The bulk electronic conductivities of POMs can be adjusted by organic grafting of desired functional groups, especially the grafting of anilido or xylidino derivatives is known to increase electronic mobility via $\mathrm{d}-\pi$ electronic transitions. ${ }^{13}$ Due to the large molecular weights, appealing densities and increased electronic mobilities via $\mathrm{d}-\pi$ interactions, organo-imido POMs gained our attention for LIB applications.

Herein, we present for the first time, the fabrication of LIBs using pure organically grafted POMs as anodes. In this present investigation the organically functionalized Lindqvist POMs

Recently, Song et al. reported interesting behaviour of organically functionalized Keggin POM hybridized with carbon nanotubes. ${ }^{\mathbf{1 0}}$ However, organically functionalized POMs in pristine state have not been explored in LIBs yet. Covalent functionalization of POMs $^{11}$ including organoimido grafting ${ }^{12}$ will hopefully open up

${ }^{a}$ Department of Chemistry, Tsinghua University, Beijing, 100084, China. E-mail: yonggewei@mail.tsinghua.edu.cn

${ }^{b}$ Department of Materials Science and Engineering College of Engineering, Peking University, Beijing, 100871, China.E-mail: hou@pku.edu.cn

$\dagger$ Electronic supplementary information (ESI) available: Single crystal XRD data along with detailed structural diagrams, ESI-MS, ${ }^{1} \mathrm{H}-\mathrm{NMR}$ spectrum, IR-spectrum, UV-Vis spectrum, CV graph and TGA plot for new hybrid compound $\left(\mathrm{Mo}_{6}-\mathrm{SCN}\right)$ available in ESI. CCDC 969621. For ESI and crystallographic data in CIF or other electronic format see DOI: $10.1039 / \mathrm{c} 3 \mathrm{ra} 46645 \mathrm{k}$

\$ These authors contributed equally.

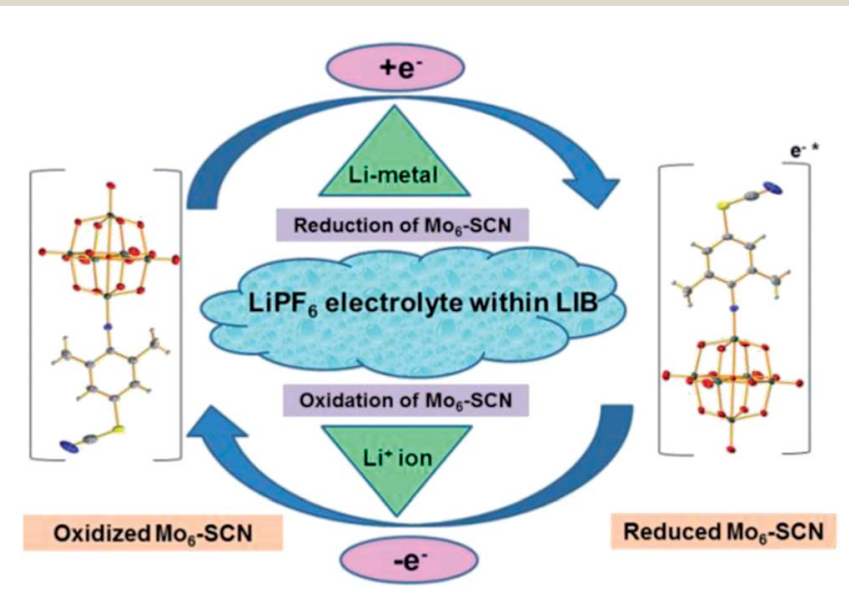

Scheme 1 Schematic redox reactions within organo-POM anode. 
have been synthesized and used as anode material, as shown in Scheme 1 above. They exhibited excellent performance and cyclic stability as compared to all POMs and their composites used yet, to the best of our knowledge. In general, organo-imido POMs have been proved to be emerging materials for the LIBs. The practical and theoretical investigations performed here, hopefully, will open a new field for researchers considering energy storage devices.

\section{Experimental}

For utilization in LIBs we considered anilinium derivatized Lindqvist hexamolybdates, due to their strong $d-\pi$ electronic mobilities. Furthermore, a remote electron withdrawing group over phenyl ring of anilido moiety was considered. Such a group can enhance electronic mobility effectively. For this purpose a ligand, 2,6-dimethyl-4-thiocyano aniline (Org-SCN) has been synthesized according to the method ${ }^{\mathbf{1 4}}$ discussed below. OrgSCN was converted to its hydrochloride salt and further reacted with $\alpha$-octamolybdate using DCC (DCC $=N, N$-dicyclohexylcarbodiimide) protocol ${ }^{12 e_{f} f}$ as mentioned below in detail.

\subsection{Synthesis of [2,6-dimethyl-4-thiocyano aniline] (Org- SCN)}

Org-SCN has been synthesized via a slight modification of an already established synthetic route. ${ }^{14}$ 2,6-Dimethyl aniline in an amount of $35 \mathrm{mmol}$ has been added in well stirred violet color solution of $52.5 \mathrm{mmol}$ of iodic acid and $77 \mathrm{mmol}$ of ammonium thiocyanate in $100 \mathrm{~mL}$ chloroform. The reaction was carried for 6 hours and monitored via thin layer chromatography; finally reaction mixture was diluted with $200 \mathrm{~mL}$ of chloroform. The diluted reaction mixture was washed two times with $200 \mathrm{~mL}$ sodium bicarbonate saturated solution in water followed by washing with $350 \mathrm{~mL}$ of brine solution. The organic product mixture was then dried over anhydrous magnesium sulfate and concentrated via vacuum rotary evaporator. The crude product was further purified using column chromatography using petroleum ether and ethyl acetate (9:1) as solvent system.

\subsection{Synthesis of organo-imido hexamolybdate $\left[\left(\mathrm{Bu}_{4} \mathrm{~N}\right)_{2}\left[\mathrm{Mo}_{6} \mathrm{O}_{18}-\mathrm{N}-\mathrm{Ph}-\left(o-\mathrm{CH}_{3}\right)_{2}-\boldsymbol{p}-\mathrm{SCN}\right]\left(\mathrm{Mo}_{6}-\mathrm{SCN}\right)\right.$}

The new hybrid $\mathrm{Mo}_{6}-\mathrm{SCN}$ has been made following the standard imidoylization procedure. ${ }^{12 e f f} 1 \mathrm{mmol}$ of octamolybdate were taken in a round bottom flask along with $1.34 \mathrm{mmol}$ of hydrochloride salt of Org-SCN and $2.2 \mathrm{mmol}$ of DCC. The reaction mixture was refluxed for about three hours in $10 \mathrm{~mL}$ of acetonitrile. The resulting solution was filtered to separate precipitated by-product $N, N^{\prime}$-dicyclohexylurea (DCU) and filtrate was added to $250 \mathrm{~mL}$ of ether. The resulting residue, after separating unreacted octamolybdate, through dissolution in acetone and successive filtration, was washed alternatively with ether and ethyl acetate for several times and then dissolved in acetonitrile and put on crystallization via diffusion method. After several days orange red crystals suitable for single crystal XRD were afforded in about $30 \%$ overall yield (the yield of crude product was found to be $45 \%$ ).

\subsection{Fabrication of anode for Li-ion batteries and electrochemical measurements}

LAND CT2001A analyzer has been used for electrochemical measurements of prepared samples. For this purpose, different current rates with a potential window of $0-3 \mathrm{Vvs} . \mathrm{Li}^{+} / \mathrm{Li}$ has been used. The cell which was made for testing, consisted of twoelectrodes, (1) lithium foil acted both as counter electrode as well as reference electrode, (2) working electrode made of active material, conductive agent (acetylene black), and polymer binder (polytetrafluoroethylene, PTFE) in a weight ratio of $40: 50: 10$ respectively. This material was mortared, prepared and then pasted onto copper foil as electron collector substrate. A temperature of $110{ }^{\circ} \mathrm{C}$ was used to dry the pasted material. The material drying time was 14 hours to completely get rid of water vapors and solvent contents. The separator was composed of Celgard 2300 membrane. $1 \mathrm{M} \mathrm{LiPF}_{6}$ solution in ethylene carbonate (EC)-dimethyl carbonate (DMC) $(1: 1 \mathrm{v} / \mathrm{v})$ was used as electrolyte within the LIB. Argon-filled glove box (Advanced instruments Inc. GPR 1900) was used for the assembling of cells; during the assembly process moisture and oxygen content were kept below $1 \mathrm{ppm}$. A scan rate of $0.2 \mathrm{mV} \mathrm{s}^{-1}$ between 0 and $3 \mathrm{~V}$ was used to investigate the cyclic voltammetry (CVs) of the material.

\subsection{Computational details}

All the calculations presented in this work were carried out with the Gaussian-03 program package. ${ }^{15}$ The structures of $\left[\left(\mathrm{Bu}_{4} \mathrm{~N}\right)_{2}\left[\mathrm{Mo}_{6} \mathrm{O}_{18}-\mathrm{N}-\mathrm{Ph}-\left(O-\mathrm{CH}_{3}\right)_{2}\right]\left(\mathrm{Mo}_{6}-\mathrm{H}\right)\right.$ and $\left[\left(\mathrm{Bu}_{4} \mathrm{~N}\right)_{2}\left[\mathrm{Mo}_{6} \mathrm{O}_{18^{-}}\right.\right.$ $\mathrm{N}$-Ph- $\left.\left(o-\mathrm{CH}_{3}\right)_{2}-p-\mathrm{CH}_{3}\right]\left(\mathrm{Mo}_{6}-\mathrm{CH}_{3}\right)$ were fully optimized using the B3LYP method, ${ }^{16}$ in combination with the LANL2DZ basis set for molybdate atoms and the $6-31 \mathrm{G}(\mathrm{d})$ basis set for the rest of the atoms, while the structure of $\mathrm{Mo}_{6}-\mathrm{SCN}$ was taken as the crystal structure. To obtain the orbital energy, the natural bond orbital (NBO) ${ }^{\mathbf{1 7}}$ analysis was further performed.

\section{Results and discussion}

\subsection{Structural characterization of $\mathrm{Mo}_{6}-\mathrm{SCN}$}

$\mathrm{Mo}_{6}-\mathrm{SCN}$ was characterized via IR, UV-Vis, ESI-MS, ${ }^{1} \mathrm{H}-\mathrm{NMR}$, single crystal XRD, TGA and elemental analysis. IR spectrum shows peaks around 952 and $796 \mathrm{~cm}^{-1}$ that can easily be assigned to the stretching vibrations of $\mathrm{Mo}_{\mathrm{t}} \mathrm{O}_{\mathrm{t}}$ and $\mathrm{Mo}-\mathrm{O}_{\mathrm{b}}-\mathrm{Mo}$ groups respectively, while characteristic peaks at about 975 and $2155 \mathrm{~cm}^{-1}$ belong to $\mathrm{Mo} \equiv \mathrm{N}$ and $\mathrm{C} \equiv \mathrm{N}$ (from $-\mathrm{SCN}$ group), respectively (Fig. S1†). UV-Vis data shows significant bathochromic shift due to $\mathrm{d}-\pi$ transitions, nearly from $325 \mathrm{~nm}$ for hexamolybdate $\left(\mathrm{Mo}_{6}\right)$ to about $365 \mathrm{~nm}$ for hybrid compound $\mathrm{Mo}_{6}-\mathrm{SCN}$ (Fig. S2 $\dagger$ ). ESI-MS of $\mathrm{Mo}_{6}-\mathrm{SCN}$ (Fig. S3 $\dagger$ ) shows clearly resolved peaks at $\mathrm{m} / \mathrm{z}$ about 520 for $\left[\mathrm{Mo}_{6} \mathrm{O}_{18}\left(\mathrm{~N}-\mathrm{Ph}-\left(\mathrm{CH}_{3}\right)_{2}-\right.\right.$ $\mathrm{SCN})]^{2-}$, and at $m / z$ about 1284 for $\left(\mathrm{Bu}_{4} \mathrm{~N}\right)\left[\mathrm{Mo}_{6} \mathrm{O}_{18}\left(\mathrm{~N}-\mathrm{Ph}-\left(\mathrm{CH}_{3}\right)_{2}-\right.\right.$ $\mathrm{SCN})]^{-}$. The ${ }^{1} \mathrm{H}$ NMR spectrum (Fig. S4†) shows the triplets at 0.97 and $3.11 \mathrm{ppm}$, while sextet and pentet at 1.36 and $1.61 \mathrm{ppm}$, respectively can easily be assigned to $\mathrm{Bu}_{4} \mathrm{~N}$ cation, while the singlet shifts at 2.61 and $7.27 \mathrm{ppm}$ are assigned to methyl groups hydrogen and phenyl ring hydrogen, respectively. Elemental analysis (\%) calcd for $\mathrm{C}_{41} \mathrm{H}_{82} \mathrm{~N}_{4} \mathrm{Mo}_{6} \mathrm{O}_{19} \mathrm{~S}$ (1542.82 $\mathrm{gmol}^{-1}$ ): $\mathrm{C}$ 


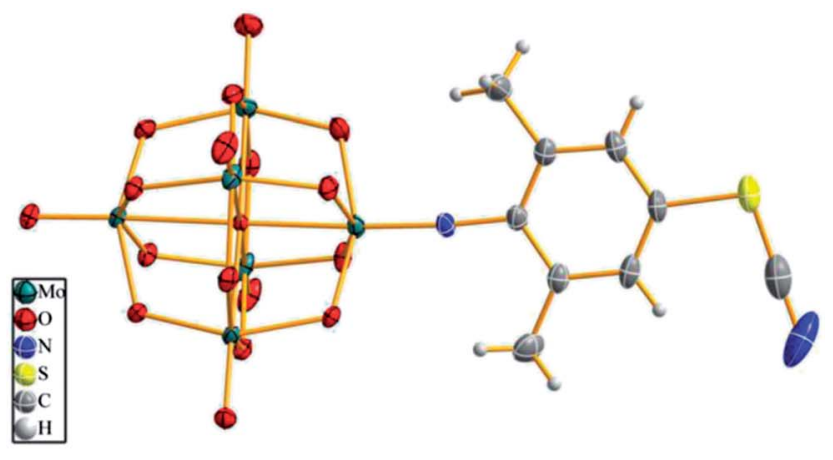

(a)

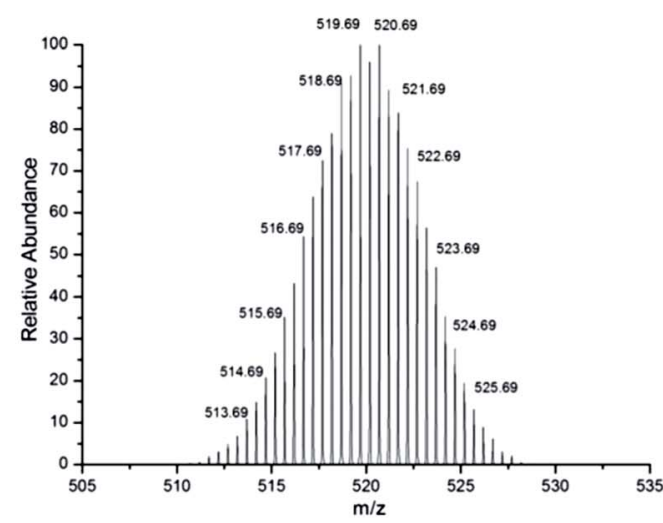

(b)

Fig. 1 (a) ORTEP diagram of anionic cluster of compound $\mathrm{MO}_{6}-\mathrm{SCN}$. $\mathrm{C}$ gray; $\mathrm{H}$ white; $\mathrm{N}$ blue; $\mathrm{O}$ red; Mo green; $\mathrm{S}$ yellow (25\% probability ellipsoids). (b) Enlarged ESI-MS of $\left[\mathrm{Mo}_{6}-\mathrm{SCN}\right]^{2-}$ anion.

31.918, H 5.357, N 3.631; found: C 31.75, H 5.52, N 3.68. Single crystal XRD data of $\mathrm{Mo}_{6}-\mathrm{SCN}$ crystal reveals that $\mathrm{Mo}_{6}-\mathrm{SCN}$ crystallizes in triclinic crystal system with space group $P \overline{1}$ (Table $\mathrm{S} 1 \dagger$ ). The structure of hybrid $\left(\mathrm{Mo}_{6}-\mathrm{SCN}\right)$ has been shown in Fig. 1a, which resembles the reported organoimido-derivatized hexamolybdates with a $\mathrm{Mo} \equiv \mathrm{N}$ triple bond, evidenced by the short bond length $(1.725(5) \AA)$ and nearly linear $\mathrm{Mo} \equiv \mathrm{N}-\mathrm{C}$ angle $\left(173.5(6)^{\circ}\right)$. Moreover, it exists as dimer form (Fig. S5 $\dagger$ ) within the lattice due to hydrogen bonding and also forms a 1D chain type supramolecular structure aided by the hydrogen bonding with water molecules (Fig. S6 ${ }^{\dagger}$ ). Thermo gravimetric analysis (TGA) for $\mathrm{Mo}_{6}$ SCN (Fig. S8 $\dagger$ ) has shown stability of the $\mathrm{Mo}_{6}-\mathrm{SCN}$ to nearly $300{ }^{\circ} \mathrm{C}$. Fig. 1b shows the enlarged ESI-MS peak at the range of $520 \mathrm{~m} / \mathrm{z}$ for the resulting hybrid anion $\left[\mathrm{Mo}_{6}-\mathrm{SCN}\right]^{2-}$, for a complete ESI-MS graph see Fig. S3. $\dagger$

\subsection{Effect of organic functionalization and resulting $d-\pi$ interactions on anode performance}

In order to explore the LIB application, pure crystalline organicinorganic hybrid material $\mathrm{Mo}_{6}-\mathrm{SCN}$ was tested as anode material. Fig. 2a presents the charge-discharge curves for the $1^{\text {st }}, 2^{\text {nd }}$, $50^{\text {th }}$ and $100^{\text {th }}$ cycles of $\mathrm{Mo}_{6}-\mathrm{SCN}$, showing initial discharge and charge capacities of 1678 and $867 \mathrm{~mA} \mathrm{~h} \mathrm{~g}^{-1}$, respectively. The discharge curve follows three distinct plateaus at potential near

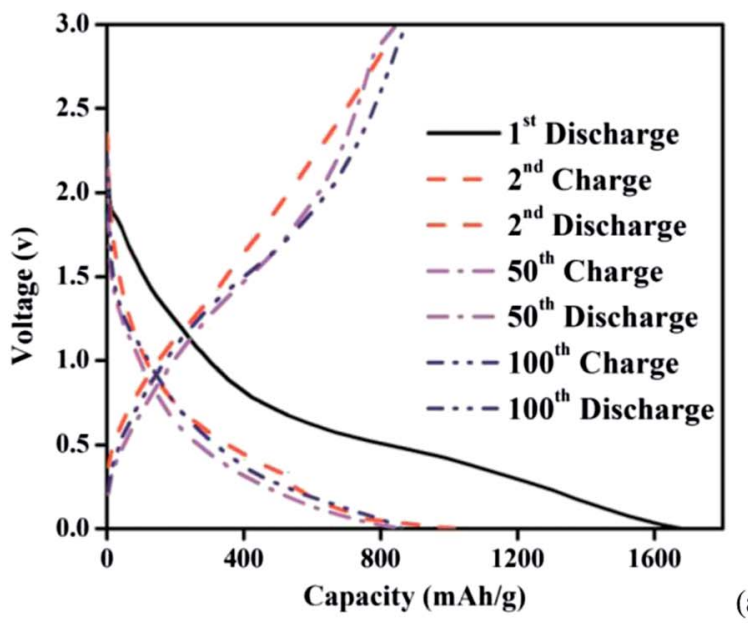

(a)

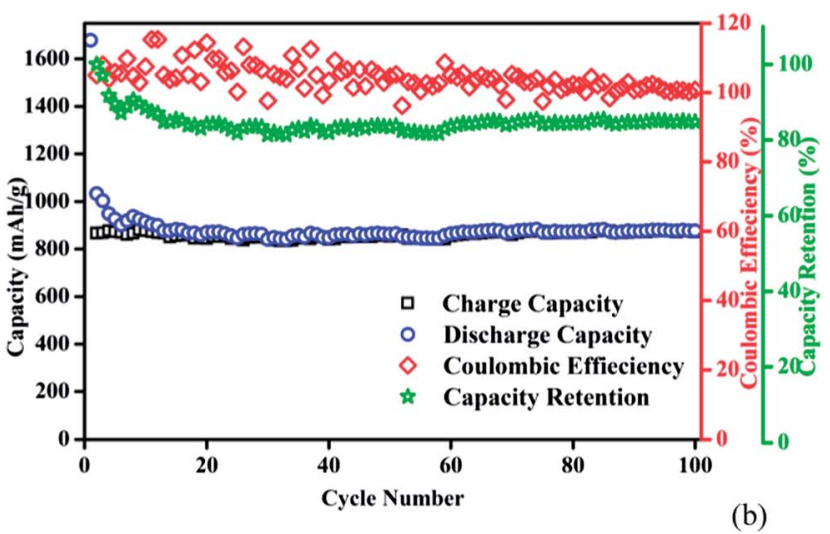

Fig. 2 (a) Charge-discharge curves of $\mathrm{Mo}_{6}-\mathrm{SCN}$ cycled $1^{\text {st }}, 2^{\text {nd }}, 50^{\text {th }}$ and $100^{\text {th }}$ tested at current density of $50 \mathrm{~mA} \mathrm{~g}^{-1}$ in the range of $0-3 \mathrm{~V}$ (vs. $\mathrm{Li}^{+} / \mathrm{Li}$ ) (b). Cycling performance, coulombic efficiency and capacity retention of $\mathrm{Mo}_{6}-\mathrm{SCN}$ tested at current density of $50 \mathrm{~mA} \mathrm{~g}^{-1}$ in the range of $0-3 \vee\left(v s . \mathrm{Li}^{+} / \mathrm{Li}\right)$.

1.8, 0.8 and $0.5 \mathrm{~V}$. Similarly the charge curve also shows a plateau at potential $1.5 \mathrm{~V}$, these redox changes confirm the reversible storage of lithium in the $\mathrm{Mo}_{6}-\mathrm{SCN}$. However, from the charge-discharge curves of $2^{\text {nd }}, 50^{\text {th }}$ and $100^{\text {th }}$ cycles it is confirmed that $\mathrm{Mo}_{6}-\mathrm{SCN}$ shows excellent capacity retention and stable cyclic life. Furthermore, the cyclic voltammetry (CV) curve of $\mathrm{Mo}_{6}-\mathrm{SCN}$ (Fig. $\mathrm{S} 7 \dagger$ ) also confirms its reversible behaviour towards lithium insertion and extraction. The basic reduction peaks appeared at 1.1 and 2.2 V. Subsequently, Fig. 2b clearly shows the cyclic behaviour of the $\mathrm{MO}_{6}-\mathrm{SCN}$ with excellent coulombic efficiency $\sim 100 \%$ up to 100 cycles. The $\mathrm{Mo}_{6}-\mathrm{SCN}$ maintained a stable capacity of $876 \mathrm{~mA} \mathrm{~h} \mathrm{~g}^{-1}$ up to 100 cycles, showing excellent performance and cyclic stability with extra ordinary capacity retention of $85 \%$ (calculated using discharge capacity from $2^{\text {nd }}$ to $100^{\text {th }}$ cycle). The coulombic efficiency that is apparently little more than $100 \%$ during most of the testing is due to the release of extra $\mathrm{Li}^{+}$ions intercalated by the active material because of four hour pre-lithiation before the testing in order to increase the stability of the cell. Thus, the high capacity, excellent capacity retention and extraordinary cyclic stability are based on the $d-\pi$ interactions that mobilize the 
electronic network of the $\mathrm{Mo}_{6}-\mathrm{SCN}$. The capacity showed by $\mathrm{Mo}_{6}-\mathrm{SCN}$ Lindqvist material is higher than previously reported for direct ${ }^{9}$ and composited use of POMs in LIBs. ${ }^{10}$ These observations directly depict the importance of organic functionalization in POMs for LIBs application. The higher first discharge capacity corresponds to the formation of solid electrolyte interface (SEI) on the surface of electrode. ${ }^{2}$ However, the stable charge-discharge capacity and high capacity retention proves that there is no further formation of SEI film and depletion of electrolyte as a result excellent cyclic stability comes out. The reason for the loss of small capacity in the initial cycles might be due to a partial isomerization of polyoxometalate materials. ${ }^{9}$ The current investigation unambiguously depicts two important facts: first, Lindqvist POMs can be engineered for use in electronic applications through organic functionalization using appropriate functional group; second, the organo-imido POMs can be used in pure form for the LIBs application with high capacities.
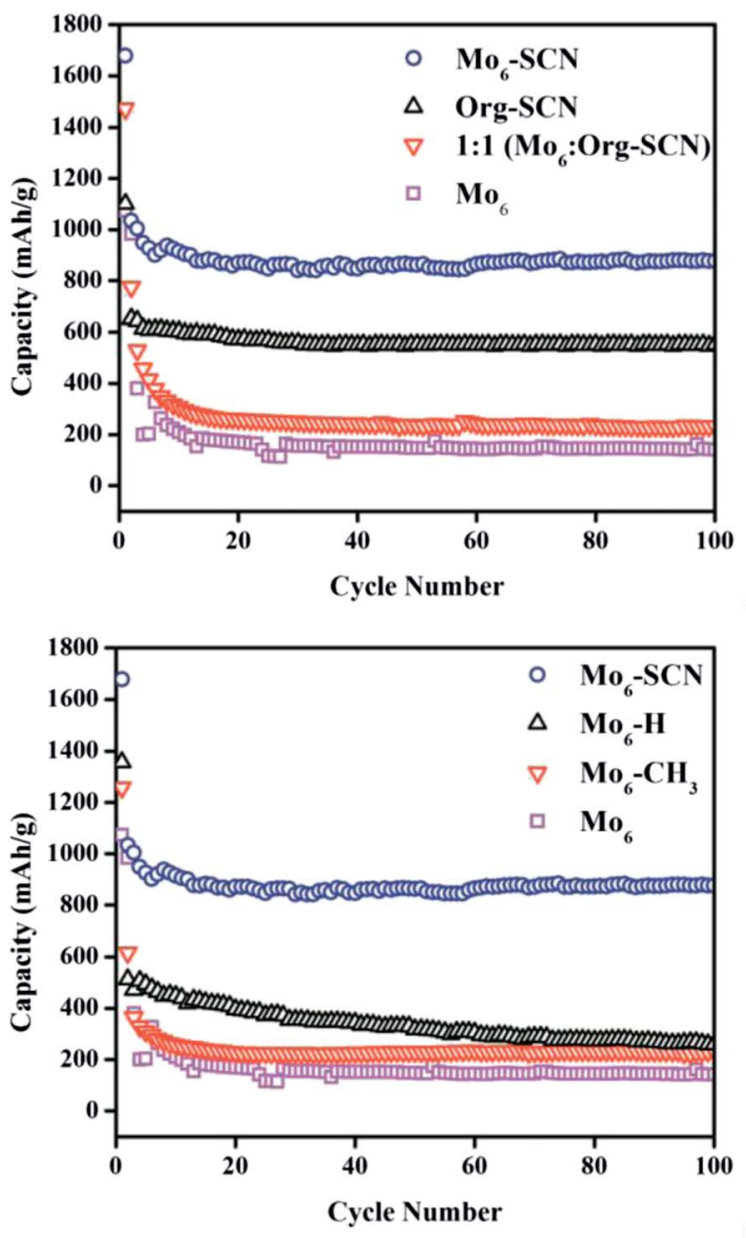

(a)

Fig. 3 (a) Comparison of cyclic performance for (1) $\mathrm{Mo}_{6}-\mathrm{SCN}$, (2) Org-SCN, (3) solid $1: 1$ ratio of $\mathrm{Mo}_{6}$ and Org-SCN, and (4) $\mathrm{Mo}_{6}$ tested at current density of $50 \mathrm{~mA} \mathrm{~g}^{-1}$ in the range of $0-3 \mathrm{~V}\left(\mathrm{vs} . \mathrm{Li}^{+} / \mathrm{Li}\right)(\mathrm{b})$. Comparison of cyclic performances for (1) $\mathrm{Mo}_{6}-\mathrm{SCN}$, (2) $\mathrm{Mo}_{6}-\mathrm{H}$, (3) $\mathrm{Mo}_{6}-\mathrm{CH}_{3}$, and (4) $\mathrm{Mo}_{6}$ tested at current density of $50 \mathrm{~mA} \mathrm{~g}^{-1}$ in the range of $0-3 \vee$ (vs. $\mathrm{Li}^{+} / \mathrm{Li}$ ), indicating the effect of electron-withdrawing group.
The results show that performance of the hybrid is highly improved when compared with pure $\mathrm{Mo}_{6}$, pure Org-SCN and even with the equimolar (1:1) solid mixture of $\mathrm{Mo}_{6}$ and OrgSCN. These observations have been summed up in Fig. 3a, which clearly shows the different performances of the investigated materials. Fig. 3a displays that the pure Org-SCN shows initial capacity at about $1101 \mathrm{~mA} \mathrm{~h} \mathrm{~g}^{-1}$ and keep the capacity values nearly at $553 \mathrm{~mA} \mathrm{~h} \mathrm{~g}{ }^{-1}$, while $\mathrm{Mo}_{6}$ merely starts from $1074 \mathrm{~mA} \mathrm{~h} \mathrm{~g}^{-1}$ and decreases immediately in further cycles to nearly $140 \mathrm{~mA} \mathrm{~h} \mathrm{~g}^{-1}$ at $100^{\text {th }}$ cycle of testing. In contrast the covalent based organic-inorganic hybrid $\mathrm{Mo}_{6}-\mathrm{SCN}$ material starts nearly from $1678 \mathrm{~mA} \mathrm{~h} \mathrm{~g}^{-1}$ and sustains its performance at about $876 \mathrm{~mA} \mathrm{~h} \mathrm{~g}^{-1}$ at $100^{\text {th }}$ cycle of testing with extraordinary capacity retention of $85 \%$. Hence, these observations clarify that organic moiety increase the electrochemical response of the POM cluster. From the results it is also obvious that $d-\pi$ interaction is necessary that increase the electronic conductivity, ion transfer mobility and structural stability of the $\mathrm{Mo}_{6}$ as poor performance was found for the physically mixed (1:1 ratio) sample of Org-SCN and $\mathrm{Mo}_{6}$.

\subsection{Effect of alteration of remote functional groups on anode performance}

Aforementioned intriguing results inculcated interest to observe the effect of remote functional groups at anode performance. In this regard, three different hybrid compounds were chosen, first with the -SCN group as model electron withdrawing group $\left(\mathrm{Mo}_{6}-\mathrm{SCN}\right)$, second with $-\mathrm{H}$ atom as model compound having no apparent functional group effect $\left(\mathrm{Mo}_{6}-\mathrm{H}\right)$, and third with a remote methyl group as a model electron donating group $\left(\mathrm{Mo}_{6}-\mathrm{CH}_{3}\right)$. All studied functional groups were substituted at para-position with respect to $\mathrm{Mo} \equiv \mathrm{N}$ bond. For this purpose hexamolybdate derivatized with 2,6-dimethylaniline and 2,4,6-trimethylaniline, named as $\mathrm{Mo}_{6}-\mathrm{H}$ and $\mathrm{Mo}_{6}-\mathrm{CH}_{3}$, were synthesized using DCC protocol ${ }^{12 e}$ and tested for their battery performances. From Fig. $3 \mathrm{~b}$ it is obvious that all imidoderivatives behave better than hexamolybdate $\left(\mathrm{Mo}_{6}\right)$. However, electron withdrawing group (-SCN) has a profound effect for the mobilization of electronic density, due to the increased metal to ligand charge transfer, making the POMs appealing for battery applications. The electron donating group $\left(-\mathrm{CH}_{3}\right)$ in contrast cannot prove much effective for electronic mobilization thus resulting in insignificant performance. If we have a look at the relative performances we can observe that all organoimido products shown much higher performances as compared to $\mathrm{Mo}_{6}$ itself. The $\mathrm{Mo}_{6}-\mathrm{H}$ starts at about $1356 \mathrm{~mA} \mathrm{~h} \mathrm{~g}^{-1}$ for first cycle and ends up at about $258 \mathrm{~mA} \mathrm{~h} \mathrm{~g}^{-1}$ for $100^{\text {th }}$ cycle of testing, while $\mathrm{Mo}_{6}-\mathrm{CH}_{3}$ having a remote electron donating group $-\mathrm{CH}_{3}$, starts at about $1256 \mathrm{~mA} \mathrm{~h} \mathrm{~g}{ }^{-1}$ for $1^{\text {st }}$ cycle and shows about $253 \mathrm{~mA} \mathrm{~h} \mathrm{~g}^{-1}$ at $100^{\text {th }}$ cycle. Both of these products show far less performance as compared to $\mathrm{Mo}_{6}-\mathrm{SCN}$ that displays about $876 \mathrm{~mA} \mathrm{~h} \mathrm{~g}{ }^{-1}$ for $100^{\text {th }}$ cycle of testing. In conclusion, it is stated that the electron withdrawing group is required to make POMs to act as effective electrode material for LIBs through mobilization of their electronic cloud via $\mathrm{d}-\pi$ transitions. The electron-withdrawing groups (-SCN), help to 


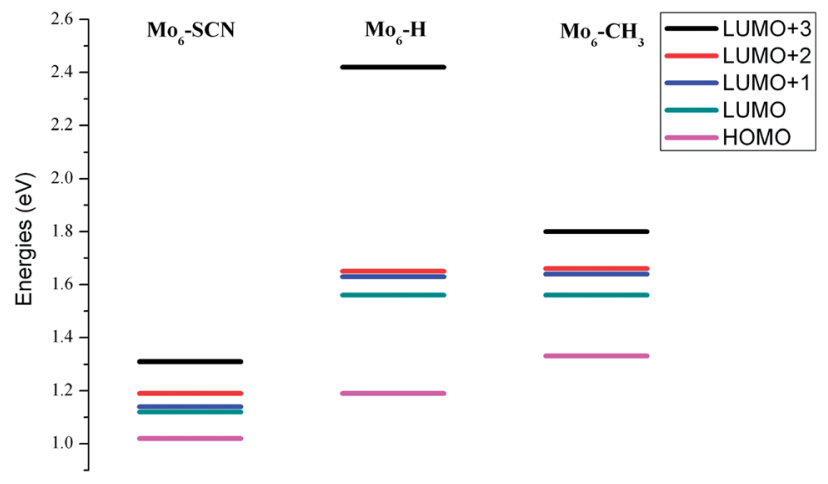

Fig. 4 Frontier molecular orbitals (FMOs, HOMO-LUMO + 3) energy level diagram for $\mathrm{Mo}_{6}-\mathrm{SCN}, \mathrm{Mo}_{6}-\mathrm{H}$ and $\mathrm{Mo}_{6}-\mathrm{CH}_{3}$.

accommodate the electron-density over the POM cluster towards the phenyl ring via $\mathrm{d}-\pi$ conjugation, hence make the POM cluster less negative. This promotes reversible reduction and oxidation of Mo-metal centres to make the organo-POM material appealing for LIB application.

\subsection{Explanation of higher anode performance for $\mathrm{Mo}_{6}-\mathrm{SCN}$ via theoretical investigation}

In order to explain the captivating capacities of these organoPOMs, the theoretical calculations have been performed using DFT method. As can be seen from Fig. 4, the energy of the lowest unoccupied molecular orbital (LUMO) was calculated as 1.124, 1.559 and $1.563 \mathrm{eV}$ in compounds $\mathrm{Mo}_{6}-\mathrm{SCN}, \mathrm{Mo}_{6}-\mathrm{H}$ and $\mathrm{Mo}_{6}-$ $\mathrm{CH}_{3}$, respectively. It is indicated that $\mathrm{Mo}_{6}-\mathrm{SCN}$ has the highest affinity to electrons, in other words, the reduction process for $\mathrm{Mo}_{6}-\mathrm{SCN}$ is the easiest one. In addition, previous investigation has pointed out that during the discharge process the electrons are taken up by the Keggin type POMs and their capacity depends on this process. ${ }^{9 a}$ In case of $\mathrm{Mo}_{6}-\mathrm{SCN}$, the energies for LUMO $+n$ (where $n=1-3$ ) which are almost the same (shown in Fig. 4), are even considerably lower than that of LUMO in $\mathrm{Mo}_{6}-$ $\mathrm{H}$ and $\mathrm{Mo}_{6}-\mathrm{CH}_{3}$, resulting in the easiest reduction and highest accommodation of electrons for compound $\mathrm{Mo}_{6}-\mathrm{SCN}$, therefore, the compound $\mathrm{Mo}_{6}-\mathrm{SCN}$ has the highest capacity.

\section{Conclusions}

In summary, we have explored first time the application of covalently functionalized imido-hexamolybdate with Lindqvist structure in energy storage devices. It is found that imido-hexamolybdates exhibit captivating performances; especially $\mathrm{Mo}_{6}-$ SCN having the electron withdrawing group (-SCN), shows a coulombic efficiency $\sim 100 \%$ and initial discharge capacity of $\sim 1678 \mathrm{~mA} \mathrm{~h} \mathrm{~g}^{-1}$ with $\sim 85 \%$ capacity retention after 100 cycles. The reason for enhanced capacity and structural stability of POMs based anode lies in the covalent modification that brings high conductivity, faster ion transfer and structure stabilization of POMs through $d-\pi$ interactions. Hence, organic functionalization is a promising method for property enhancement and the harnessing of POMs in advanced applications. Moreover, it is found that imido-hexamolybdate with low energy of LUMO will exhibit higher capacities. Briefly, the experimental and theoretical results obtained here provide a design strategy for POM based materials from synthesis to performance. Further work regarding effect of other remote functional groups, metal centre, POM structures, and composites of organo-imido derivatized POMs with other common anodic materials on battery performance is on-going in our laboratories.

\section{Acknowledgements}

This work is sponsored by NFSC (no. 21225103, 21221062 and 51125001), THSJZ and the Tsinghua University Initiative Foundation Research Program no. 20101081771. R. N. N. Khan and N. Mahmood especially thank to Chinese Scholarship Council for providing scholarships for doctoral studies at Tsinghua University and Peking University.

\section{Notes and references}

1 (a) M. Armand and J. M. Tarascon, Nature, 2008, 451, 652; (b) P. D. Yang and J. M. Tarascon, Nat. Mater., 2012, 11, 560.

2 (a) J. B. Goodenough and K.-S. Park, J. Am. Chem. Soc., 2013, 135, 1167; (b) W. Wei, S. Yang, H. Zhou, I. Lieberwirth, X. Feng and K. Müllen, Adv. Mater., 2013, 25, 2909; (c) C. Zhang, N. Mahmood, H. Yin, F. Liu and Y. Hou, Adv. Mater., 2013, 25, 4932.

3 (a) B. Jang, M. Park, O. B. Chae, S. Park, Y. Kim, S. M. Oh, Y. Piao and T. Hyeon, J. Am. Chem. Soc., 2012, 134, 15010; (b) Y. Sun, X. Hu, J. C. Yu, Q. Li, W. Luo, L. Yuan, W. Zhang and Y. Huang, Energy Environ. Sci., 2011, 4, 2870; (c) D.-J. Xue, S. Xin, Y. Yan, K.-C. Jiang, Y.-X. Yin, Y.-G. Guo and L.-J. Wan, J. Am. Chem. Soc., 2012, 134, 2512; (d) N. Mahmood, C. Zhang, F. Liu, J. Zhu and Y. Hou, ACS Nano, 2013, 7, 10307.

4 (a) M. T. Pope, in Comprehensive Coordination Chemistry II, Elsevier, Oxford, 2004, vol. 4, p. 635; (b) C. L. Hill, in Comprehensive Coordination Chemistry II, Elsevier, Oxford, 2004, vol. 4, p. 679; (c) A. Müller, P. Kögerler and A. W. M. Dress, Coord. Chem. Rev., 2001, 222, 193; (d) D.-L. Long, E. Burkholder and L. Cronin, Chem. Soc. Rev., 2007, 36, 105.

5 (a) A. Müller and P. Gouzerh, Chem. Soc. Rev., 2012, 41, 7431; (b) M.-P. Santoni, A. K. Pal, G. S. Hanan, A. Proust and B. Hasenknopf, Inorg. Chem., 2011, 50, 6737; (c) Z.-M. Zhang, S. Yao, Y.-G. Li, X.-B. Han, Z.-M. Su, Z.-S. Wang and E.-B. Wang, Chem. - Eur. J., 2012, 18, 9184; (d) N. V. Izarova, M. T. Pope and U. Kortz, Angew. Chem., Int. Ed., 2012, 51, 9492; (e) S. Wang, X. Lin, Y. Wan, W. Yang, S. Zhang, C. Lu and H. Zhuang, Angew. Chem., Int. Ed., 2007, 46, 3490; (f) Y. Hou, M. Nyman and M. A. Rodriguez, Angew. Chem., Int. Ed., 2011, 50, 12514; $(\mathrm{g})$ J. M. Breen and W. Schmitt, Angew. Chem., Int. Ed., 2008, 47, 6904.

6 (a) L. C. Palilis, M. Vasilopoulou, D. G. Georgiadou and P. Argitis, Org. Electron., 2010, 11, 887; (b) M. Sessolo and H. J. Bolink, Adv. Mater., 2011, 23, 1829. 
7 (a) S.-X. Guo, Y. Liu, C.-Y. Lee, A. M. Bond, J. Zhang, Y. V. Geletii and C. L. Hill, Energy Environ. Sci., 2013, 6, 2654; (b) H. Lv, Y. V. Geletii, C. Zhao, J. W. Vickers, G. Zhu, Z. Luo, J. Song, T. Lian, D. G. Musaev and C. L. Hill, Chem. Soc. Rev., 2012, 41, 7572; (c) B. Matt, J. Fize, J. Moussa, H. Amouri, A. Pereira, V. Artero, G. Izzet and A. Proust, Energy Environ. Sci., 2013, 6, 1504; (d) F. Song, Y. Ding, B. Ma, C. Wang, Q. Wang, X. Du, S. Fu and J. Song, Energy Environ. Sci., 2013, 6, 1170.

8 (a) F.-J. Ma, S.-X. Liu, C.-Y. Sun, D.-D. Liang, G.-J. Ren, F. Wei, Y.-G. Chen and Z.-M. Su, J. Am. Chem. Soc., 2011, 133, 4178; (b) C. Musumeci, M. H. Rosnes, F. Giannazzo, M. D. Symes, L. Cronin and B. Pignataro, ACS Nano, 2011, 5, 9992; (c) P. Yin, P. Wu, Z. Xiao, D. Li, E. Bitterlich, J. Zhang, P. Cheng, D. V. Vezenov, T. Liu and Y. Wei, Angew. Chem., Int. Ed., 2011, 50, 2521; (d) H. Fu, C. Qin, Y. Lu, Z.-M. Zhang, Y.-G. Li, Z.-M. Su, W.-L. Li and E.-B. Wang, Angew. Chem., Int. Ed., 2012, 51, 7985; (e) M. Ibrahim, Y. Lan, B. S. Bassil, Y. Xiang, A. Suchopar, A. K. Powell and U. Kortz, Angew. Chem., Int. Ed., 2011, 50, 4708.

9 (a) H. Wang, S. Hamanaka, Y. Nishimoto, S. Irle, T. Yokoyama, H. Yoshikawa and K. Awaga, J. Am. Chem. Soc., 2012, 134, 4918; (b) N. Sonoyama, Y. Suganuma, T. Kume and Z. Quan, J. Power Sources, 2011, 196, 6822; (c) S. Uematsu, Z. Quan, Y. Suganuma and N. Sonoyama, J. Power Sources, 2012, 217, 13.

10 (a) N. Kawasaki, H. Wang, R. Nakanishi, S. Hamanaka, R. Kitaura, H. Shinohara, T. Yokoyama, H. Yoshikawa and K. Awaga, Angew. Chem., Int. Ed., 2011, 50, 3471; (b) D. Ma, L. Liang, W. Chen, H. Liu and Y.-F. Song, Adv. Funct. Mater., 2013, 23, 6100; (c) M. Lira-Cantú and P. Gómez-
Romero, Chem. Mater., 1998, 10, 698; (d) P. Gómez-Romero and M. Lira-Cantú, Adv. Mater., 1997, 9, 144.

11 A. Proust, R. Thouvenot and P. Gouzerh, Chem. Commun., 2008, 1837.

12 (a) Y. Du, A. L. Rheingold and E. A. Maatta, J. Am. Chem. Soc., 1992, 114, 345; (b) J. B. Strong, G. P. A. Yap, R. Ostrander, L. M. Liable-Sands, A. L. Rheingold, R. Thouvenot, P. Gouzerh and E. A. Maatta, J. Am. Chem. Soc., 2000, 122, 639; (c) W. Clegg, R. J. Errington, K. A. Fraser, S. A. Holmes and A. Schafer, J. Chem. Soc., Chem. Commun., 1995, 455; (d) A. Proust, R. Thouvenot, M. Chaussade, F. Robert and P. Gouzerh, Inorg. Chim. Acta, 1994, 224, 81; (e) Y. Wei, B. Xu, C. L. Barnes and Z. Peng, J. Am. Chem. Soc., 2001, 123, 4083; $(f)$ P. Wu, Q. Li, N. Ge, Y. Wei, Y. Wang, P. Wang and H. Guo, Eur. J. Inorg. Chem., 2004, 2004, 2819. 13 (a) M. R. S. A. Janjua, C.-G. Liu, W. Guan, J. Zhuang, S. Muhammad, L.-K. Yan and Z.-M. Su, J. Phys. Chem. A, 2009, 113, 3576; (b) M. Lu, B. Xie, J. Kang, F.-C. Chen, Y. Yang and Z. Peng, Chem. Mater., 2005, 17, 402; (c) J. Gao, X. Liu, Y. Liu, L. Yu, Y. Feng, H. Chen, Y. Li, G. Rakesh, C. H. A. Huan, T. C. Sum, Y. Zhao and Q. Zhang, Dalton Trans., 2012, 41, 12185.

14 U. S. Mahajan and K. G. Akamanchi, Synth. Commun., 2009, 39, 2674.

15 M. J. Frisch, G. W. Trucks, H. B. Schlegel, et al., Gaussian 03, revision E.01, Gaussian, Inc., Wallingford, CT, 2004.

16 (a) A. D. Becke, J. Chem. Phys., 1993, 98, 5648; (b) C. T. Lee, W. T. Yang and R. G. Parr, Phys. Rev. B: Condens. Matter Mater. Phys., 1988, 37, 785.

17 A. E. Reed, L. A. Curtiss and F. Weinhold, Chem. Rev., 1988, 88, 899. 